\title{
Research on the Significance of Development on the Platform Economy
}

\author{
Ye Xiumin \\ Center for Informatization Study of Chinese Academy of Social Sciences, Beijing, China
}

\section{Email address:}

xmye@cass.org.cn

\section{To cite this article:}

Ye Xiumin. Research on the Significance of Development on the Platform Economy. Science Journal of Business and Management. Vol. 5, No. 2, 2017, pp. 54-58. doi: 10.11648/j.sjbm.20170502.12

Received: January 1, 2017; Accepted: March 2, 2017; Published: March 10, 2017

\begin{abstract}
The platform economyRepresented by the Internet platform is developing quikly. It has integrateddeeply intopeople's work and life.It has changed the way of the production and operation of an enterprises. It has brought the profound influence to the whole economic and social development.It has epoch-making historical significance. This paper gives four aspects of significance to developplatform economy: leading the rapid development of the new economy, meetingthe users' personalized and diversified needs, promoting public entrepreneurship and SME innovation, advancing the adjustment of industrial structure and the transformation of the mode of economic development.
\end{abstract}

Keywords: Platform Economy, Sharing Economy, "Internet +"

\section{Introduction}

Alibaba listed on the NYSE in september 2014. The total market capitalization reached $\$ 238$ billion, which is more than Facebook. It became the largest U.S. stock market IPO. The recent development strategy of Alibaba claims that it is seeking to create an open, transparent, collaborative infrastructure platform for business. Alibaba's beautiful performance has caused the world's attention to the internet platform and platform economy. With the implementation of "Internet+" plan as well as the technology development and Internet application. The platform economy is developing more rapidly. More and more business platforms have emerged, and they have given rise to a new platform economic tide.

The Internet platform is rising quickly, and it has driven the growth of related fieldsand formed platform economy gradually. The base of the platform economic is the internet and other modern information technology. The platform provide differentiated services to the multi subjects. The platform integrate multi subject relationship in order to create value and make the multi subject to maximize the benefits of a new economy. There are also some experts and scholars on the definition of the platform economy. The first scholar who proposed the platform economics defines is $\mathrm{Xu}$ Jin. From the perspective of platform business model, he believes that "the platform economy is a kind of business model for appropriate costs and benefits which can facilitate transactions between parties". DongBaoqing, a director of Central network security and Informatization Leading Group, has highly summarized the role of platform economy. He said: "from the perspective of IT, the platform is a system of systems; from the perspective of popular speaking, the platform is an enterprise of enterprises". XuBingsheng spoke highly of the positive role played by the platform economy, he believes that the platform is an innovative form of economic development and the platform is reconstructing of the industrial chain.

Although the platform economy is developing rapidly, but the theoretical research on the platform economy lags behind the practice development. Research on traditional platform economy mostly focuses on bilateral market theory. Researchers generally believe that the bilateral market has two important characteristics: One is that the huge number of users led to the bilateral market with network externalities; the second is that the core of the platform is the price structure. Platform enterprise can adjust the price structure so that the seller and the buyer will stay in the platform. Rochet and Tirole (2003) made a pioneering study of the bilateral market, and defined it from the perspective of price structure. Armstrong (2006) from the point of view of network 
externalities, believe the two sides of the transaction is the transaction between the two sides through the platform, and the income of either party depends on the number of the other party. Roson (2005) defined two-sided market a kind of economy environment. In the bilateral market, goods (or service) are provided to two different groups of users, there is a positive correlation between the users' profits and the number of the other group of users.

Therefore, the market will erupt between various conflicts and contradictions in the economic activities, such as the regulatory responsibility of the platform, the monopoly of the platform, etc.. The practice of platform economy calls for the deepening and innovation of relevant theories in order to give more guidance to economic activities. In the last two years, the author of this article has made a deep investigation into the platform enterprise, such as CAXA, Taobao, DIDI, and Qingdao RedCollar. The author puts forward the main points of this paper, combined with literature research and accumulated over the years.

\section{The Present Situation of Platform Economy}

China's platform economy is presenting the characteristics of large scale, more quantity and fast growth.

\subsection{Large Scale of Platform Economy}

China's platform economy continues to grow rapidly in recent years. Data [1] shows that the size of China's network economy (Internet Co revenue size) amounted to 8706.2 billion Yuan in 2014, an increase of $47 \%$, which is one of the most promising emerging industries. In the field of online advertising as an example, according to Analysys International data, China's Internet advertising industry scale reached 153.5 billion Yuan in 2014, and it is continuing its rapid growth. Baidu's advertising revenue exceeded CCTV in 2013, which is becoming the largest advertising media in China.

\subsection{More Quantity of Platform Economy}

The scale of platform enterprise grows rapidly, which are playing a very important role in the development of the platform economy. According to the report released by the CNNIC shows that the total number of sites in China reached more than 4.14 million, the total number of domain names is more than 22.3 million. There are 12.25 million. $\mathrm{CN}$ domain names, which is ranked the second place in the world. Moreover, China's major Internet listing Corporation are platform enterprises. There are 328 Internet platform enterprises [2] listed in lately five years. The market capitalization is about 7.85 trillion Yuan, equaling to $25.6 \%$ of the total market capitalization of China's stock market. In particular, Alibaba, Tencent, Baiduand Jingdong have entered the top 10 global Internet company. In other areas of the Internet, there are also a number of leading platform enterprises, such as Alipay, Tuniu, Vipshop, Didi Taxietc.

\subsection{Fast Growth of Platform Economy}

Platform economy is sustaining rapid growth, as a dazzling star in new economy. Take WeChat as an example, the number of its active users has reached 549 billion only after a few years since its birth in 2011, as shown in the following figure. Its users have covered more than 20 countries and more than $90 \%$ of the smartphone. We Chat has become an indispensable daily tool in people's life. E-commerce is also a kind of typical platform economy, China's e-commerce transaction volume has achieved double-digit growth year by year. In 2014, for example, amounted to 13 trillion Yuan [3] equivalent to $20.43 \%$ of the GDP of the year, an increase of 1.6 percentage points over the previous year. E-commerce transactions increased by $25 \%$, compared to the growth rate of $7.4 \%$ of GDP, e-commerce is still one of the most promising emerging industries in China. Online retail market grows strongly, too. Its transaction size is 2.8 billion Yuan, equivalent to $10.69 \%$ of the total retail sales of social consumer goods, an increase of 2.8 percentage points over the previous year.

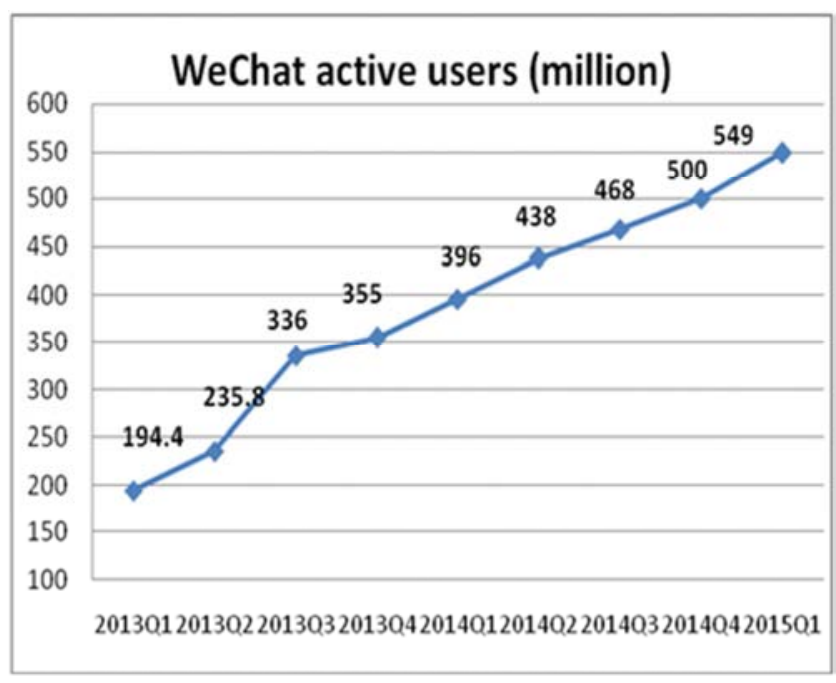

Figure 1. WeChat active users (million).

\section{Significance of Developing Platform Economy}

The platform economy is developing quikly. It has integrated deeply into people's work and life. It is changing the way of the production and operation of an enterprises. It is also becoming the new engine of economy. It has brought far-reaching influence to the economic and social development.

\subsection{Leading the Rapid Development of the New Economy}

The bilateral market characteristic of the platform economy innovates new industry model and forms new industry status. The new economic market boundaries continue to expand with rapid growth. The vigor of platform economy reflects in four aspects: First, its market is verylarge. 
There are millions of loyal users in wide scope. Second, its innovation is speeding up greatly in the fields of new technology, new applications, new mode and new platform. Third, its scale is very large in the figures of total industrial scale, platform quantity and market size. Fourth, its growth is rather fast. There are huge potential chance in the area of innovation, market, platforms and other multiple field. Fifth, its radiation is strong, the platform is playing a leading role for other subject in the value chain and the platform economy is driving other economic forms to develop.

The market size of platform economy continues to grow rapidly. According to the data from IResearch, China's network economy market size (sum of revenue of the internet Co) amounted to 870.6 billion Yuan in 2014, an increase of $47 \%$. It is one of the most promising emerging industries in China. Among them, revenue of PC internet economy is 637.7 billion Yuan and revenue of the mobile internet economy is 222.9 billion Yuan. Many segments are showing rapid growth. In the field of e-commerce, for example, transactions of Chinese e-commerce reached 13 trillion Yuan [4] in 2014, as shown in the following figure, equivalent to $20.43 \%$ of GDP of that year, an increase of 1.6 percentage points over the previous year. Online retail also pushed up express business in China, according to the data from State Post Bureau, China's express business volume reached 14 billion, an increase of $52 \%$, ranking first in the world in 2014.

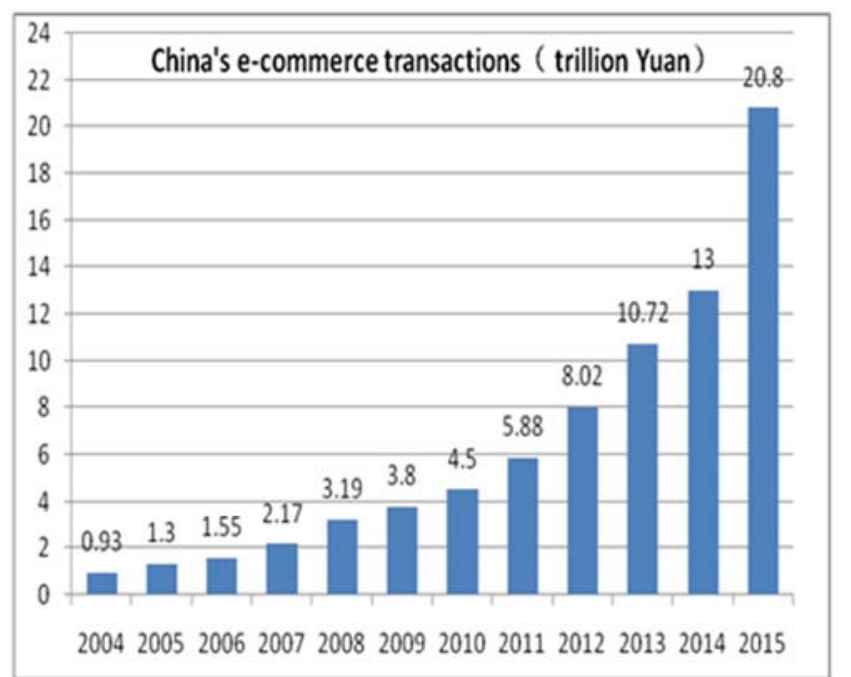

Figure 2. China's e-commerce transactions.

Platform enterprises play an increasingly important role in the development of new economy. China's major Internet listed companies are all platform enterprises. The top five of the market value are shown in the following table.

Table 1. The top five of the market value.

\begin{tabular}{ll}
\hline company & market value(Billion dollars) \\
\hline Alibaba & 253.4 \\
Tencent & 135.5 \\
Baidu & 80.3 \\
Jingdong & 31.5 \\
Netease & 13.0 \\
\hline
\end{tabular}

Platform companies continue to develop rapidly. The number of active users has reached 549 billion monthly. In the first quarter of 2015, Alibaba revenue reached 600 billion Yuan, an increase of $40 \%$.

\subsection{Meeting the Users' Individualized and Diverse Demand}

Platform economic has penetrated into people's lives. Service provided by the platform is richer and more interactive. It can meet the growing users' personalized and diversified needs better. It also can stimulate domestic demand and promote consumption. Modern people pay more attention to the themselves, so the demand for personalized products and services is more and more strong. Platform just can provide the mass and one to one service to meet the users' needs. The internet platform is open to more subjects so that they can provide users with a wide range of alternative services. The total number of Apple App Store applications reaches 1.5 million. There are 8 million professional sellers in Taobao. The social network platform, such as WEChat has accelerated the exchange of information among people. E-commerce has changed the consumption patterns. The third-party payment platform, such as Alipay has brought a more safe and convenient payment service. The life platform, such as 58.com, has facilitated the people's daily life......

China's online retail market transaction scale has reached 280 million Yuan in 2014, equivalent to $10.69 \%$ of the total retail sales of social consumer goods, an increase of 2.8 percentage points over the previous year. Online retail market has kept a rapid growth, an increase of $49.7 \%$, which is 4 times faster than the growth ofthe total retail sales of social consumer goods. In addition, according to the data from McKinsey released on Chinese online retail sales report, $61 \%$ of China's online retail consumption belongs to the transfer of consumption from offline, other $39 \%$ is new consumer demand that stimulated by the internet.

Moreover, the application of Internet platform is also gradually deepening in China's financial, education, medical, transportation and other fields. Internet platform is prompting the means of public service networking and platforming. Online transfer accounts, social networks, online classes, online registration, hospital registration with WeChat, ordering dinner by the phone has been closely linked with people's daily life. The platform is becoming an important driving force for the change of interpersonal relationship, life style and social structure.

- Case Study: Mobile Travel platform for the convenience of travel

Uber was founded in 2009 in the United States, located in mobile travel platform, designed to enhance the travel experience, to provide passengers with a high-end and more private travel plans. Uber integrates automotive resources. Uber connects the users' needs and automotive resources in use of large data technology, so that consumers can take a taxi nearby more quickly. Uber innovates the ways to travel. It has improved resource utilization efficiency and reduced the rate of empty driving to save energy. Moreover, passengers can choose their favorite car model and enjoy the 
driver's personalized service to improve travel satisfaction. Uber will continue to be involved in the other areas of service in the future, such as medical and catering services. Currently, Uber's valuation is $\$ 50$ billion, becoming the world's highest valuation of the unlisted companies.

DidiTaxi's business model is similar to that of Uber. They are all the mobile travel information platform generated in the past two years. DidiTaxi's market is experiencing an explosive growth because of price subsidies and strong promotion. According to the report released at the beginning of 2015, the users' scale of Didi Taxi has exceeded 150 million and orders quantity in the peak day has reached 1.22 million. DidiTaxi and Quick Taxi announced a merger in 2015. The merge will helpful for the new company, not only to increase the market share, but also to avoid the vicious competition in the industry.

\subsection{Promoting Public Entrepreneurship and SMEs 'Innovation}

Platform economy not only leads the new economic development, driving the transformation and upgrading of traditional enterprises, but also becomes the support for a large number of the internet users and of the SMEs to innovate.

First, the Internet platform promotes information sharing, so that the entrepreneurs can grasp the market information quickly in a fair competition area, to avoid the market risk of information asymmetry. Internet platform can convergea huge amount of data. Big data mining can help SMEs to carry out precision marketing and to promote service transformation.

Secondly, the Internet platform provide resource sharing and mutual opportunities for the entrepreneurs and SMEs, which is helpful to reduce $\mathrm{R} \& \mathrm{D}$ costs and to improve efficiency. In the open cloud service platform, service outsourcing has gradually been welcomed. Cloud service platform has built a communication bridge for the service providers and the users. Most of users are SMEs, who are usually unable to set up $\mathrm{R} \& \mathrm{D}$ department with high cost. They can release demand through the cloud platform. Then they can get a targeted solution with low cost. Developers are able to design and develop according a variety of specific needs and provide targeted services. In addition, SMEs are also a service provider in an open platform where they can butt big business directly and access to opportunities fairly.

Finally, the Internet platform is just an entrepreneurial space providing a convenient and suitable environment for the SMEs' innovation. It can reduce the threshold of innovation and entrepreneurship. Setting up online shop on the e-commerce platform can deal with business at home. It is a great change of the way of entrepreneurship and employment. According to the "online entrepreneurship and employment Research Report" released by Ministry of human resources and social security, China's online employment and entrepreneurship has accumulated more than 10 million job opportunities. It has alleviated the employment pressure effectively in recent years. It is of great signifycance to improve the entrepreneurial income and happiness.

\subsection{Promoting the Adjustment of Industrial Structure and the Transformation of Economic Development Mode}

Platform economy has penetrated into the traditional areas. It is driving the traditional economic transformation, as well as it is leading the economic growth.

\subsubsection{Promoting the Development of Modern Service Industry}

Platform economy also has given birth to the emergence and development of e-commerce services industry which is the most famous star leading the development of modern service industry. Subdivision fields of e-commerce servicesindustry, such as warehousing and logistics, the third-party payment, consulting services, call center services, e-commerce outsourcing services, investment and financing services, are all showing a trend of rapid growth. Revenueof e-commerce services reached 246 billion Yuan, an increase of $72 \%$ in 2012. According to the data of State Post Bureau, China's express delivery business scale reached 14 billion, an increase of 52\%, ranking first in the world in 2014. The payment institutions has dealt with the 21.5 billion pieces of internet payment business, involved business scale 17.05 trillion Yuan [6], an increase of $43.52 \%$ and $90.29 \%$.

\subsubsection{Promoting the Traditional Enterprise to Accelerate the Pace of Transformation}

E-commerce platform is helpful for traditional industries to expand the marketing channels. Traditional retail and manufacturing enterprises have increased the Internet transformation and begun to find the market on the Internet platform in order to respond to the environmental changes. Clothing, household product, household electrical appliances, digital products, outdoor products, building materials, etc. have become the main areas of online retail. Alibaba and HC360 are wholesale e-commerce platform. Taobao and Jingdong are integrated retail e-commerce platform. Jumei.com, yougou.com and OkBuy are all vertical retail platforms in different areas.

Internet platform facilitates enterprises to integrate resources to rebuild efficient value network. The value chain of traditional industries is usually the linear chain of the upstream and downstream, which is long and Inefficient. It has disadvantages of high cost, limited selectivity. Platform has broken the traditional industrial cooperation in the linear chain relationship and formed a value network. On the Internet platform, a variety of resources can be barrier free communication, free docking, to facilitate the rapid allocation of resources. It is good for the enterprise to facilitate the rapid deployment of resources. On the Internet platform, enterprises can not only preferred partners, but also set up timely interaction relations with the users, service providers, capital, employee and even the machine. According to user's needs, the enterprises can response Immediately to establish virtual organization, to start agile 
manufacturing, to achieve mutual benefit at last.

Platform economy is helpful to promote the transformation of traditional industry to improve the core competitiveness. Platform economy makes it possible to collect information, make decisions and react quickly. In terms of information acquisition ability, the enterprise can capture the change of market information in real time, so it can response quickly and sensitively, to change the business strategy and to adapt to the market demand. In terms of the organizational structure, the enterprise can change the organizational structure in the guide of user's demand. Every organization of the enterprise is linked by the management system, which is more flat and more close to the user, so as to enhance strain capacity and improve efficiency. In terms of business model, the platform communicates each link including of production, marketing and management. From the enterprise from merchandise sales turn for service demand of the user, all the subjects are devoted to in the mission of fulfill users'needs. At last, all subjects have targeted around the needs of the market to promote the transformation from manufacturing industry to service industry.

In brief, it is of great significance to develop platform economy. Platform economy is promoting technological innovation and promoting public entrepreneurship and innovation. It is accelerating the new economy to boom. It is promoting the transformation of traditionalindustry to realize the upgrading of the industrial structure. It is making the deep integration of Industrialization and informatization into reality.

\section{Conclusion}

With the rapid development of platform economy, it has integrated into all aspects of people's work and life more and more deeply. It is changing the way of production and operation of enterprises and people's way of life. As a new engine to promote economic development, platform economy has brought far-reaching impact on the entire economic and social development, with the historical significance of the landmark. We should study the law on the platform economy deeply, and promote the development of the platform economy actively.

\section{References}

[1] Source: Iresearch, «2015 China network economy annual monitoring report», July 2015.

[2] Source: Cnnic, «"the12th Five-Year Plan" ten major highlightsof China's Internet development».

[3] Source: website of the Ministry of Commerce, « China e-commerce report (2014)», May 2015.

[4] Source: China payment and Settlement Association, «China payment and settlement industry operation report (2014)», May 2014.

[5] Andrei Hagiu. Proprietary vs. Open Two-sided platforms and Social Efficiency [J]. Harvard Business School working paper. $2006(3)$.

[6] Gaudeu A, Jullien B. E-commerce, two-sided markets and info-mediation. Communications \& Strategies ${ }^{\wedge} \mathrm{OO}^{\wedge}$ ieflJriy-SS.

[7] KatsamakasE; Bakos Y. Design and ownership of two-sided networks. Jounal of Economic Perspectives ${ }^{\wedge}$ OOS. 1SfZj ${ }^{\wedge} \mathrm{S}-\mathrm{IZO}$.

[8] Nocke, Volker. Peitz, Martin. Stahl, Konrad. PLATFORM OWNERSHIP [J]. Journal of the European Economic Association, vol.5. Blackwell Publishing Ltd, 1542-4774, 1130-1160, 2007.

[9] Thomas Eisenmann, Geoffrey Parke ${ }^{\wedge}$ Marshall Van Alstyne. Platform EnveIopment [J]. Strategic Management Journal. 32:1270-1285(2011).

[10] T. H. Davenport and J. C. Beck. The Attention Economy: Understanding the New Currency of Business [J]. Harvard Business School Press, 2001. 